\title{
Aplikasi Pemberian Pupuk NPK dan Pengaturan Air terhadap P-Tersedia, Serapan P dan Hasil Padi Sawah (Oryza Sativa L.) pada Inceptisols Asal Jatinangor
}

\author{
Asti Asfianti1, Emma Trinurani S2, Anni Yuniarti' ${ }^{2}$ dan Eso Solihin'1 \\ ${ }^{1}$ Alumni Program Magister Ilmu Tanah, Fakultas Pertanian \\ 2)Staff Pengajar Departemen Ilmu Tanah dan Sumberdaya Lahan, Fakultas Pertanian \\ Universitas Padjadjaran, Jl. Raya Bandung Sumedang Km 21 Jatinangor \\ Koresponden : asti.asfianti@yahoo.com
}

\begin{abstract}
This research was conducted to find out the effect of application NPK compound and water regulation on soil phosphorus, P uptake and yield of rice (Oryza sativa L.) on Inceptisols. The study was conducted from in late May to October 2015. at the field station of soil and water management, Soil Science and Land Resources Department, Faculty of Agriculture, Padjadjaran University, Jatinangor, Sumedang. The experimental design used was Randomized Block Design (RBD) with ten treatments and three replications, consisted of : without treatment (control), waterlogged $5 \mathrm{~cm} ; 150$ $\mathrm{kg} \mathrm{Ha}^{-1}$, waterlogged $5 \mathrm{~cm} ; 300 \mathrm{~kg} \mathrm{Ha}^{-1}$, waterlogged $5 \mathrm{~cm} ; 450 \mathrm{~kg} \mathrm{Ha}^{-1}$, waterlogged $5 \mathrm{~cm} ; 600 \mathrm{~kg}$ $\mathrm{Ha}^{-1}$, waterlogged $5 \mathrm{~cm} ; 750 \mathrm{~kg} \mathrm{Ha}^{-1}$, waterlogged $5 \mathrm{~cm}$; local recommended dosage, waterlogged 5 $\mathrm{cm} ; 450 \mathrm{~kg} \mathrm{Ha}{ }^{-1}$, macak-macak; $450 \mathrm{~kg} \mathrm{Ha}^{-1}$, intermittent 1 day, macak-macak; $450 \mathrm{~kg} \mathrm{Ha}^{-1}$, intermittent 3 days, macak-macak. The results showed that there were effect of soil phosphorus, $P$ uptake and yield of Rice on Inceptisol. Suppy NPK dose of $750 \mathrm{~kg}$ ha-1 were waterlogged $5 \mathrm{~cm}$ provides the highest content of available P amounted to $51.88 \mathrm{ppm} P, P$ uptake of $0.93 \%$ and the highest yield of $9.24 \mathrm{~kg} \cdot \mathrm{ha}^{-1}$.
\end{abstract}

Keywords : Inceptisols, NPK fertilizer, waterlogged, rice

\section{PENDAHULUAN}

Padi merupakan tanaman yang banyak dibudidayakan di Indonesia. Penyediaan beras bagi penduduk Indonesia yang selalu bertambah memerlukan upaya nyata dalam peningkatan produksi padi (Makarim dan Suhartatik, 2006). Berdasarkan data hasil SUSENAS - BPS dalam Pusat Data dan Sistem Informasi Pertanian (2013), konsumsi beras pada tahun 2012 yaitu 97,65 kg/kapita/tahun. Kebutuhan pangan meningkat seiring dengan pertambahan jumlah penduduk. Pertumbuhan penduduk Indonesia melaju dengan cepat yaitu 1,49\% per tahun pada periode tahun 1990-2000 dan untuk tahun 2013 dengan laju pertumbuhan 1,3\% per tahun. Tuntutan akan peningkatan produksi padi juga ikut meningkat selama diversifikasi makanan pokok tidak optimal dilakukan.

Peningkatan produksi padi diantaranya dipengaruhi intensifikasi dan ekstensifikasi pertanian, salah satu lahan yang potensial dikembangkan adalah Inceptisol. Menurut Agus dkk. (2004) Inceptisol di Indonesia mempunyai distribusi yang luas yaitu $\pm 70,52$ juta ha, tersebar hampir di seluruh daratan Indonesia. Namun, dalam proses pengembangannya beberapa kendala diantaranya adalah kesuburan tanah yang tegolong rendah. Kesuburan tanah menjadi faktor yang sangat penting karena berkaitan dengan kandungan unsur hara yang ada di dalam tanah. Pemupukan dan pengelolaan lahan yang tepat dilakukan untuk membantu meningkatkan kemampuan lahan serta mengurangi pengaruh sifat kimia Inceptisols yang kurang baik terhadap tanaman, khusunya tanaman padi.

Padi sawah merupakan salah satu tanaman pangan yang mampu tumbuh pada tanah yang tergenang air, tumbuh pada tanah kering dan air dalam. Berdasarkan sistem perakarannya, tanaman padi bukan sepenuhnya tanaman air, sehingga mempunyai sifat semiakuatis (Hardjowigeno dan Rayes, 2005).

Penggenangan tanah akan mengakibatkan perubahan sifat kimia tanah yang akan mem- 
pengaruhi tanaman padi. Perubahan sifat kimia antara lain penurunan kadar oksigen dalam tanah, penurunan potensial redoks, perubahan $\mathrm{pH}$ tanah, reduksi $\mathrm{Fe}$ dan $\mathrm{Mn}$, peningkatan suplai dan ketersediaan $\mathrm{N}$, pe-ningkatan ketersediaan P (Ponnamperuma, 1976).

Pupuk NPK merupakan salah satu pupuk anorganik yang dapat digunakan dalam meningkatkan ketersediaan unsur hara makro N, $\mathrm{P}$, dan $\mathrm{K}$, menggantikan pupuk tunggal. Pupuk anorganik dalam budidaya tanaman merupakan salah satu usaha untuk meningkatkan kualitas dan kuantitas hasil tanaman. Pupuk majemuk ini hampir seluruhnya larut dalam air, sehingga unsur hara yang dikandungnya dapat segera diserap dan digunakan oleh tanaman dengan efektif (Kaya, 2013).

\section{BAHAN DAN METODE}

Percobaan dilaksanakan di Kebun Percobaan Pengelolaan Tanah dan Air, Departemen Ilmu Tanah dan Sumberdaya Lahan, Fakultas Pertanian Universitas Padjadjaran, Jatinangor. Ketinggian tempat berada pada 725 meter di atas permukaan laut. Jenis tanah termasuk ke dalam ordo Inceptisol. Pelaksanaan Percobaan mulai bulan Mei sampai dengan Oktober 2015.

Percobaan menggunakan Rancangan Acak Kelompok Tunggal dengan sepuluh perlakuan, yaitu:
A. tanpa pupuk, digenangi $5 \mathrm{~cm}$
B. $150 \mathrm{~kg} \mathrm{NPK} \mathrm{ha}{ }^{-1}$, digenangi $5 \mathrm{~cm}$
C. $300 \mathrm{~kg} \mathrm{NPK} \mathrm{ha}^{-1}$, digenangi $5 \mathrm{~cm}$
D. $450 \mathrm{~kg} \mathrm{NPK} \mathrm{ha}^{-1}$, di-genangi $5 \mathrm{~cm}$
E. $\quad 600 \mathrm{~kg} \mathrm{NPK} \mathrm{ha}^{-1}$, digenangi $5 \mathrm{~cm}$
F. $750 \mathrm{~kg} \mathrm{NPK} \mathrm{ha}^{-1}$, digenangi $5 \mathrm{~cm}$
G. anjuran setempat: $200 \mathrm{~kg}_{\text {Urea ha- }}^{-1}, 75$ $\mathrm{kg} \mathrm{ha}^{-1}, 50 \mathrm{~kg} \mathrm{ha}^{-1}$, digenangi $5 \mathrm{~cm}$
H. $450 \mathrm{~kg}$ NPK ha-1 dengan pengairan macak-macak
I. $450 \mathrm{~kg}$ NPK ha-1 dengan pengairan selang 1 hari sampai macak-macak
J. $450 \mathrm{~kg}$ NPK ha-1 dengan pengairan selang 3 hari sampai macak-macak

Masing-masing dengan tiga kali ulangan. Varietas padi yang digunakan adalah Inpari 31.
Data hasil pengamatan dianalisis dengan sidik ragam pada tingkat kepercayaan $95 \%$. Pengujian lanjut perbedaan antar perlakuan dilakukan dengan Uji Jarak Ganda Duncan pada tingkat kepercayaan $95 \%$.

\section{HASIL DAN PEMBAHASAN}

\subsection{P-Tersedia}

Hasil uji statistik menunjukkan terdapat perbedaan yang nyata antara pemberian NPK majemuk dan pengaturan air terhadap ketersedian Fosfor di dalam tanah. Hal ini dikarenakan pengaruh penambahan pupuk NPK dan faktor penggenangan sehingga mampu meningkatkan kelarutan fosfor yang ada di dalam tanah.

Menurut Prasetyo, dkk (2004), peningkatan ketersediaan $\mathrm{P}$ akibat penggenangan disebabkan oleh pelepasan $\mathrm{P}$ yang dihasilkan selama proses reduksi. Sedangkan penambahan pupuk NPK dapat langsung tersedia bagi tanaman setelah pupuk tersebut diberikan ke dalam tanah.

Tabel 1 Pengaruh Aplikasi NPK dan Pengaturan Air terhadap P-tersedia Tanah

\begin{tabular}{|c|c|c|}
\hline & Perlakuan & $\begin{array}{l}\mathrm{P}- \\
\text { tersedia }\end{array}$ \\
\hline A & $\begin{array}{l}\text { Tanpa pupuk, digenangi } 5 \mathrm{~cm} \\
\text { (kontrol) }\end{array}$ & $29,69 \mathrm{a}$ \\
\hline B & $150 \mathrm{~kg} \mathrm{NPK} \mathrm{ha}^{-1}$, digenangi $5 \mathrm{~cm}$ & $35,42 \mathrm{~b}$ \\
\hline $\mathrm{C}$ & $300 \mathrm{~kg} \mathrm{NPK} \mathrm{ha}^{-1}$, digenangi $5 \mathrm{~cm}$ & $37,04 \mathrm{bc}$ \\
\hline $\mathrm{D}$ & $450 \mathrm{~kg} \mathrm{NPK} \mathrm{ha}^{-1}$, digenangi $5 \mathrm{~cm}$ & $41,85 \mathrm{de}$ \\
\hline $\mathrm{E}$ & $600 \mathrm{~kg} \mathrm{NPK} \mathrm{ha}^{-1}$, digenangi $5 \mathrm{~cm}$ & $48,83 \mathrm{f}$ \\
\hline $\mathrm{F}$ & $750 \mathrm{~kg} \mathrm{NPK} \mathrm{ha}^{-1}$, digenangi $5 \mathrm{~cm}$ & $51,88 \mathrm{f}$ \\
\hline G & $\begin{array}{l}\text { Anjuran setempat: } 200 \mathrm{~kg}^{-} \text {Urea ha- } \\
1,75 \mathrm{~kg} \mathrm{ha}^{-1} \mathrm{TSP}, 50 \mathrm{~kg} \mathrm{ha}^{-1} \mathrm{KCl} \text {; } \\
\text { digenangi } 5 \mathrm{~cm}\end{array}$ & $44,39 \mathrm{e}$ \\
\hline $\mathrm{H}$ & $\begin{array}{l}450 \mathrm{~kg} \mathrm{NPK} \mathrm{ha}^{-1} \text { dengan pengairan } \\
\text { macak-macak }\end{array}$ & $42,13 \mathrm{de}$ \\
\hline I & $\begin{array}{l}450 \mathrm{~kg} \text { NPK ha-1 dengan pengairan } \\
\text { selang } 1 \text { hari sampai macak-macak }\end{array}$ & $39,95 \mathrm{~cd}$ \\
\hline $\mathrm{J}$ & $\begin{array}{l}450 \text { kg NPK ha-1 dengan pengairan } \\
\text { selang } 3 \text { hari sampai macak-macak }\end{array}$ & $37,92 \mathrm{bc}$ \\
\hline & $\begin{aligned} \text { gan: } & \text { Angka-angka ya } \\
& \text { sama tidak berb } \\
& \text { jarak berganda D }\end{aligned}$ & \\
\hline
\end{tabular}




\subsection{Serapan $P$}

Pengaruh pemberian pemberian NPK majemuk dan pengaturan air terhadap serapan fosfor pada tanaman setelah diuji statistik menunjukan perbedaan yang nyata antara perlakuan (Tabel 2). Perlakuan F dengan dosis 750 kg NPK ha-1 ${ }^{-1}$ digenangi $5 \mathrm{~cm}$ menunjukkan perbedaan yang nyata dan serapan $P$ tertinggi dibandingkan dengan kontrol dengan peningkatan serapan sebesar 106,67 \%.

Tabel 2 Pengaruh Aplikasi NPK dan Pengaturan Air terhadap serapan P Tanah

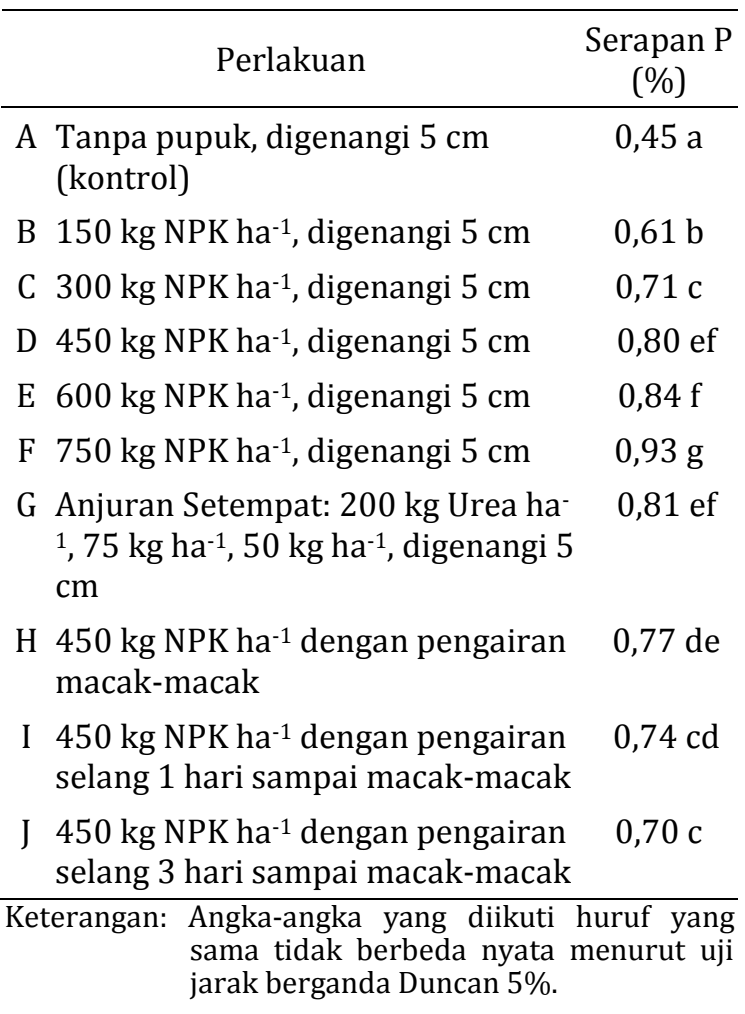

Pada perlakuan A (tanpa pupuk, digenangi $5 \mathrm{~cm}$ ) menunjukan serapan fosfor lebih rendah dibandingkan dengan perlakuan lainnya yaitu $0,45 \%$. Hal ini dikarenakan tidak ada penambahan unsur hara dari luar yang dapat meningkatkan ketersedian $\mathrm{P}$, sehingga tanaman hanya mampu menyerap hara yang disediakan oleh tanah. Pada perlakuan lain dengan adanya penambahan NPK dapat meningkatkan serapan fosfor hal terse-but terlihat dari perlakuan B, C, D, E dan F.

Pupuk NPK majemuk merupakan sumber $\mathrm{P}$, sehingga akan menjadi $\mathrm{P}$ tersedia dalam jumlah tinggi dan mudah larut sehingga mudah diserap oleh tanaman. Fosfor masuk ke dalam tanaman bersama dengan larutan di tanah masuk ke dalam zona perakaran, lalu diserap oleh bagian-bagian tanaman seperti akar, cadangan akar, lalu ke batang dan dari batang ada yang masuk ke benih dan ada juga yang masuk melalui pembuluh batang dan yang terakhir masuk ke daun (Ismunadji dkk., 1991).

\subsection{Hasil Padi}

Berdasarkan hasil uji statistik (Tabel 3), pemberian NPK majemuk dan pengaturan air berpengaruh nyata terhadap produksi padi berupa Bobot Gabah Kering Panaen (GKP). Perlakuan A (kontrol) menghasilkan bobot GKP yang paling rendah. Hal ini diakibatkan karena pada perlakuan ini tidak ada pupuk yang ditambahkan ke dalam tanah.

Tabel 3 Pengaruh NPK Majemuk dan Pengaturan Air terhadap Bobot GKP Per Petak

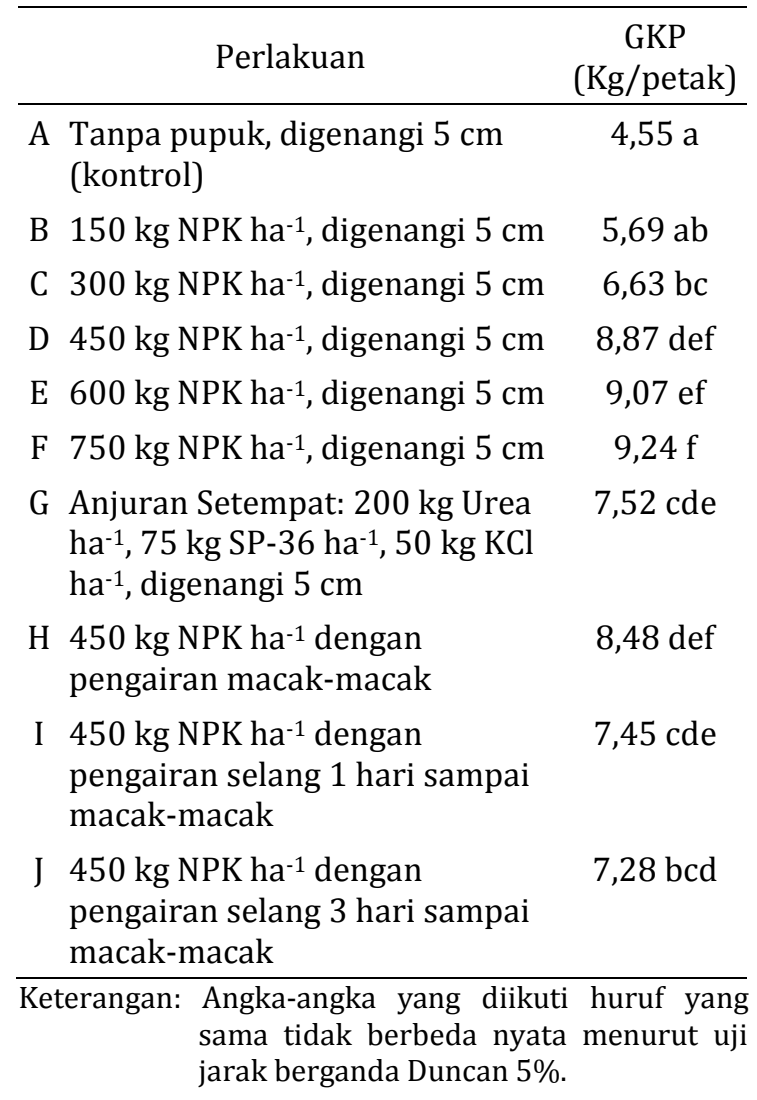

Tabel 3 menunjukan bahwa perlakuan $\mathrm{F}$ (750 kg NPK ha-1, digenangi $5 \mathrm{~cm}$ ) menunjukan peningkatan GKP tertinggi sebesar 103,08 $\%$ dibandingkan dengan perlakuan A yang tan- 
pa menggunakan pupuk NPK. Pada perlakuan

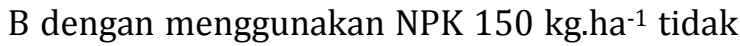
menunjukan perbedaan yang nyata jika dibanding dengan perlakuan A namun ada peningkatan hasil sebesar $25,05 \%$. Sementara perlakuan C dengan menggunakan $300 \mathrm{~kg}$ NPK ha-1 menunjukan perbedaan yang tidak nyata jika dibandingkan dengan perlakuan $\mathrm{B}$ dan terdapat peningkatan hasil $45,71 \%$ jika dibandingkan dengan kontrol.

Secara keseluruhan perlakuan dengan penambahan NPK dapat meningkatkan hasil GKP dibandingkan dengan kontrol. Hal ini dikarenakan ketersediaan unsur hara yang dibutuhkan tanaman dapat terpenuhi dengan adanya penambahan NPK yang tepat sehingga dapat mempercepat penyerapan unsur hara dan meningkatkan produksi tanaman (Nazirah dan Damanik, 2015).

\section{KESIMPULAN}

Pemberian NPK majemuk dan pengaturan air secara keseluruhan berpengaruh dalam meningkatkan P-tersedia tanah, serapan $\mathrm{P}$ tanaman dan hasil gabah kering panen (GKP). Pemberian dosis NPK $750 \mathrm{~kg} \mathrm{ha}^{-1}$ yang digenangi $5 \mathrm{~cm}$ memberikan kandungan $\mathrm{P}$ tersedia tertinggi yaitu sebesar 51,88 ppm $\mathrm{P}$, serapan $\mathrm{P}$ 0,93 \% dan terhadap hasil gabah kering panen tertinggi sebesar 9,24 kg.ha-1.

\section{DAFTAR PUSTAKA}

Agus F., Adimiharja A., Hardjowigeno S., Fagi A. M., Hartatik M (Eds). 2004. Sumberdaya Daya Lahan Indonesia dan Pengelolaannya. Pusat Penelitian dan Pengembangan Tanah dan Agroklimat. Bogor.

Hardjowigeno, S. dan Rayes, M. L. 2005. Tanah Sawah: Karakteristik, Kondisi, dan Permasalahan Tanah Sawah di Indonesia. Bayumedia. Malang.

Ismunadji. M., S. Partohardjono, dan A.S. Karama. 1991. Fosfor, Peranan dan Penggunaannya Dalam Bidang Pertanian. Balai Penelitian Tanaman Pangan. Bogor.

Kaya, E. 2013. Pengaruh kompos jerami dan pupuk NPK terhadap N-tersedia tanah, serapan $\mathrm{N}$, pertumbuhan dan hasil padi sawah (Oryza sativa L.) Prosiding FMIPA Universitas Pattimura, 2013.

Makarim, K. dan Suhartatik, E. 2006. Budi Daya Padi dengan Masukan In Situ Menuju Perpadian Masa Depan. Iptek Tanaman Pangan No. 1 - 2006.

Nazirah, L. dan Damanik B.S.J. 2015. Pertumbuhan dan hasil tiga varietas padi gogo pada perlakuan pemupukan. J. Floratek Vol 10(1) : $54-60$.

Ponnamperuma, F. N. 1976. Specifif soil chemical characteristics for rice production in Asia. IRRI Research Paper Series No. 2. The International Rice Research Institute, Manila. Philippines.

Prasetyo, B.H., J.S. Adiningsih, K. Subagyono dan R.D.M. Simanungkalit. 2004. Mineralogi, Kimia, Fisika dan Biologi Tanah Sawah Dalam Tanah Sawah dan Teknologi Pengelolaannya. Pusat Penelitian dan Pengembangan Tanah dan Agroklimat. Bogor. 